\title{
Hadis-Hadis Tentang Syafaat Dalam Kitab Sahịị Muslim
}

(Hadiths about Intercession in the Book of Saḥ Mus Muslim)

\author{
Nawir Yuslem ${ }^{1}$, Ardiansyah ${ }^{2}$, Mukhtaruddin ${ }^{3}$, \\ Ismail Fahmi Arrauf Nasution ${ }^{4 *}$ \\ 1,2UIN Sumatera Utara, ${ }^{3}$ Madrasah Ulumul Quran Langsa, ${ }^{4}$ IAIN Langsa, Indonesia \\ *Corresponding author: ismailfahmiarraufnasution@iainlangsa.ac.id
}

DOI: $10.29240 /$ alquds.v5i2.2909

Submitted: 2021-06-16| Revised: 2021-08-17|Accepted: 2021-08-22

\begin{abstract}
This article discusses the Hadith about syafaat (intercession) in Sahih Muslim using the thematic hadith approach. The term syafaat (intercession) comes from the root word syaf'u or syafā'ah which literally means intercession (help) to convey a request to Allah or mediation, intercession or intermediary between two people. The author traces the hadiths in Sahih Muslim that talk about the topic of intercession, the result is found that in Sahih Muslim this word with its various derivations (isytiqaq) is repeated 38 times spread over 30 hadiths. In terms of structure or form of expression, the terms of intercession that are spread in Sahih Muslim appear at least in five forms of invented words (isytiqaq) each of which implies different meanings. The following article discusses at least seven kinds of expression of syafaat (intercession) with various meanings with various pressures, such as the substance of intercession, the purpose of intercession, the limitations of intercession, the way to obtain intercession, the giver and recipient of intercession, the time of the appearance of intercession, and the conditions for intercession to occur. The elaboration of these topics intends to emphasize the meaning of intercession and the matters related to it..
\end{abstract}

Keyword: intercession; help; hadith; Sahih Muslim

\begin{abstract}
Abstrak. Tulisan ini membahas hadis tentang syafaat dalam Sahih Muslim dengan menggunakan pendekatan hadis tematik. Term syafaat berasal dari akar kata syaf'u atau syafäah yang secara bahasa berarti perantaraan (pertolongan) untuk menyampaikan permohonan kepada Allah atau mediasi, perantaraan atau penengah antara dua orang. Penulis menelusuri hadis-hadis dalam sahih muslim yang berbicara topik syafaat, hasilnya ditemukan bahwa dalam sahih muslim kata ini dengan berbagai derivasinya (isytiqaq) diulang sebanyak 38 kali yang tersebar dalam 30 hadis. Dilihat dari segi struktur atau bentuk pengungkapan, terma syafaat yang tersebar di dalam Sahih Muslim setidaknya muncul dalam lima bentuk kata jadian (isytiqaq) yang masing-masing implikasi makna yang berbeda-beda. Tulisan ini membahas sedikitnya tujuh macam pengungkapan syafaat
\end{abstract}


dengan berbagai pemaknaan dengan tekanan yang beragam, seperti misalnya substansi syafaat, tujuan syafaat, batasan syafaat,jalan mendapatkan syafaat, pemberi dan penerima syafaat, masa munculnyasyafaat, dan syarat terjadi syafaat. Elaborasi dari topik-topik tersebut bermaksud untuk menegaskan pemaknaan terhadap syafaat dan hal-hal yang berkaitan dengannya.

Kata Kunci : syafaat; pertolongan; hadis; sahih muslim.

\section{Pendahuluan}

Kehidupan manusia di dunia merupakan sebuah proses menuju pada kehidupan berikutnya, yaitu kehidupan di alam akhirat setelah manusia mengalami kematian dan dibangkitkan dari kematiannya. Dalam menjalani kehidupan, manusia terkadang dihadapkan pada pilihan antara melakukan amal yang baik dan jahat. Apabila seseorang melakukan amalan yang baik, maka ia akan dijanjikan surga oleh Allah. Sementara bagi yang melakukan amal kejahatan, maka ia akan dihalaukan pada siksaan dengan masuk neraka. ${ }^{1}$

Setiap mukmin yang pernah melakukan kebaikan meskipun sedikit, maka ia dapat berkemungkinan akan diberikan bantuan di akhirat, baik dengan pertolongan dari Rasulullah saw., Sadiqin, ulama, orang-orang salih ataupun dari kasih sayang serta karunia Allah atas inisiatif Allah sendiri, ${ }^{2}$ sejauh manusia yang akan mendapatkan bantuan itu tidak menyekutukan Allah (syirik).

Bantuan yang akan diperoleh manusia, baik di dunia maupun hari akhirat, sering orang menyebutnya dengan istilah syafaat. ${ }^{3}$ Syafaat juga bisa berarti perantaraan (intermediasi) atau penengah antara dua orang. Adapun kata الثََّفِْقِ

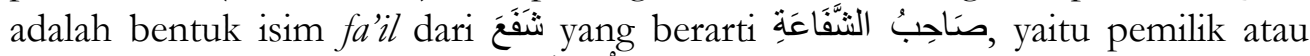
pemberi syafaat, atau bermakna الُْعْعِيْن yaitu pembela atau penolong. Sedangkan secara istilah, syafaat adalah: Pertolongan pihak ketiga kepada pihak yang membutuhkannya dalam rangka memberikan suatu manfaat atau menolak suatu mudarat ${ }^{4}$. Sebagai contoh, dalam rangka memberikan suatu manfaat adalah syafaat Nabi saw. kepada calon penghuni surga agar dapat segera masuk surga dan dalam rangka menolak suatu mudarat adalah syafaat Nabi saw. kepada calon

\footnotetext{
${ }^{1}$ Aan Supian, "Metode Syarah Fath Al-BariI (Studi Syarah Hadis pada bab Halawah alIman)," Nuansa: Jurnal Studi Islam dan Kemasyarakatan 10, no. 1 (June 10, 2017), doi:10.29300/nuansa.v10i1.632.

${ }^{2}$ Benny Afwadzi, "Tinjauan Semiotika Atas Pemahaman Hadith Dalam Kitab Fath Albari Karya Ibn Hajar Al'Asqalani," Al-A'raf: Jurnal Pemikiran Islam Dan Filsafat 17, no. 1 June 30, 2020): 97, doi:10.22515/ajpif.v17i1.1935.

${ }^{3}$ Iim Muslimah, Konsep Syafaat Menurut Pandangan Muhammad Quraish Shibab (Analisis Terbadap Tafsir Al-Misbab) (Jakarta: IIQ, 2017).

${ }^{4}$ Amin Farih, "Paradigma Pemikiran Tawassul Dan Tabarruk Sayyid Ahmad Bin Zaini Dahlan Ditengah Mayoritas Teologi Madzhab Wahaby," Jurnal Theologia 27, no. 2 (December 27, 2016): 279-304, doi:10.21580/teo.2016.27.2.1069.
} 
penghuni neraka untuk tidak masuk ke dalam api neraka atau membebaskannya dari $a z a b^{5}$.

Imam Muslim menyebutkan hadis tentang syafä'at antara lain hadis berikut ini, yaitu:

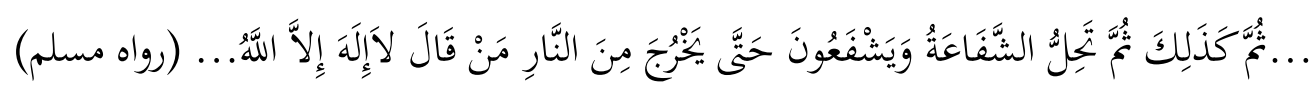

[...Kemudian syafaat diizinkan. Mereka pun meminta syafaat, sehingga mereka dapat keluar dari Neraka, yaitu orang yang mengucapkean, Là Iläha Illällah .... . (HR. Muslim) $)^{6}$.

Hadis di atas sesuai dengan ayat Alquran yang membahas tentang syafaat, antara lain firman Allah berikut ini:

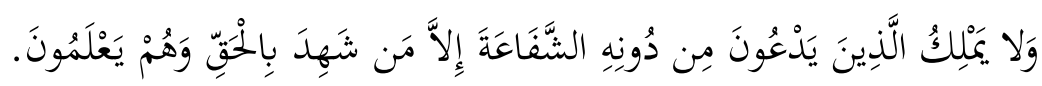

Dan sembahan-sembahan yang mereka sembah selain Allah tidak dapat memberi syafaat; akan tetapi (orang yang dapat memberi syafaat ialah) orang yang mengakui yang bak (taubid) dan mereka meyakini (nya)]. (QS. 43/ar-Zukhruf: 86)

Persoalan syafaat adalah salah satu hal yang istimewa dalam Islam dan merupakan akidah yang benar serta salah satu ajaran dari Nabi Muhammad saw. yang disampaikan kepada umatnya agar mereka dapat menghilangkan kegelisahan terhadap siksaan yang berkelanjutan di akhirat.

Berdasarkan dari penjelasan yang ada, syafaat hanya terjadi dengan izin dan kehendak dari Allah dan diberikan mandat kepada Nabi Muhammad untuk menjalankannya dan untuk memberikan kepada siapa saja yang dipilih oleh Nabi Muhammad saw. sendiri baik ketika ia masih hidup maupun bantuan yang akan diberikan di akhirat nanti ketika kehidupan baru akan dimulai.

Selain dalam Alquran yang banyak menyebutkan ayat-ayat tentang bantuan dalam bentuk syafaat yang tidak perlu diragukan lagi kesahihan dalil yang menjelaskan tentangnya, juga banyak terdapat dalam hadis termasuk hadis yang diriwayatkan oleh Imam Muslim yang tidak perlu diragukan lagi kesahihannya karena mayoritas ulama mengakuinya sebagai hadis yang sahih, maka penelitian ini berfokus pada penjelasan hadis-hadis tentang syafaat yang diriwayatkan oleh imam Muslim.

${ }^{5}$ Yuli Ayu Afriyanti, "Sang Pemberi Syafaat (Mengenal Para Pemberi Syafaat Dihari Akhir)" (INA-Rxiv, December 30, 2018), doi:10.31227/osf.io/cgxy9.

${ }^{6}$ Agusman Damanik, "Urgensi Studi Hadis di UIN Sumatera Utara," SHAHIH Jurnal Kewahyuan Islam) 1, no. 1 (August 29, 2018), doi:10.51900/shahih.v1i1.1886.

7 “Qur'an Kemenag," accessed August 17, 2021, https://quran.kemenag.go.id/. 


\section{Substansi Syafaat}

\section{Pengertian Syafaat}

Kata syafaat berasal dari bahasa Arab, yaitu“"شفاعة ـ شفعا - يشع - شفع"dan kata ini telah dijadikan sebagai bahasa Indonesia yang baku ${ }^{8}$.Secara bahasa, syafaat berarti perantaraan (pertolongan) untuk menyampaikan permohonan kepada Allah atau mediasi ${ }^{9}$. Maksudnya, perantaraan dalam memberikan sesuatu manfaat bagi orang lain atau mengelakkan sesuatu mudarat (siksa) bagi orang lain. Dengan kata lain, syafaat adalah permohonan ampunan (kepada Tuhan) atas dosa-dosa orang lain. Orang yang memberikan syafaat disebut dengan syafi, ${ }^{10}$.

Sedangkan syafaat menurut istilah adalah sebagaimana dijelaskan oleh Imam Muhammad bin Șālị̣ bin Muḥammad al-'Usaimīn (1925-2001 M) sebagai berikut:

$$
\text { والشفاعة هي التوسط للغير لجلب منفعة أو دفع مضرة }
$$

[Syafaat adalah menengahi bagi yang lain untuk mendapatkan manfaat atau menghilangkan memudaratan $]^{11}$.

Syafaat juga bisa berarti perantaraan atau penengah antara dua orang.

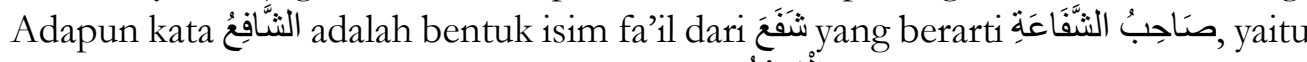
pemilik atau pemberi syafaat, atau bermakna الْمُعِيْنُ Sementara menurut Muhammad Imran menjelaskan bahwa syafaat secara syar'̄i ialah bantuan dari pihak ketiga kepada pihak lain yang membutuhkan dalam rangka memberikan suatu manfaat atau menghindari dari kemudaratan ${ }^{12}$. Syafaat semacam ini menurutnya bisa berbentuk bantuan Rasul kepada calon penghuni surga supaya segera masuk surga dan dalam rangka menghindari kemudaratan seperti bantuan Rasul kepada calon penghuni neraka supaya tidak disiksa dalam neraka atau dapat membebaskan manusia dari siksa ${ }^{13}$.

${ }^{8}$ A.W. Munawwir, Kamus Al-Munawnir Arab-Indonesia Terlengkap (Surabaya: Progressif, 1997), 1579.

${ }^{9}$ Khotim Hanifudin Najib and Achmad Habibullah, "Konstruksi Sosial Islam Moderat Jamaah Maiyah Mocopat Syafaat Pada Generasi Milenial Di Yogyakarta," Fikri : Jurnal Kajian Agama, Sosial Dan Budaya 5, no. 2 (December 31, 2020): 171-82, doi:10.25217/jf.v5i2.1175.

${ }^{10}$ Mesakh Jasmin, "Konsep Syafaat Dalam Rencana Total Allah,” Jurnal Jaffray 4, no. 1 (June 1, 2006): 34-40, doi:10.25278/ji71.v4i1.133.

${ }^{11}$ Damanik, "Urgensi Studi Hadis di UIN Sumatera Utara."

12 Muhammad Imran, "Sahabat Nabi SAW Dalam Perspektif Sunni Dan Syi'ah (Pengaruhnya Pada Kesahihan Hadis)," Aqlam: Journal of Islam and Plurality 1, no. 1 (January 31, 2018), doi:10.30984/ajip.v1i1.497.

${ }^{13}$ Ibrahim Bafadhol, "Tujuan Hidup dalam Perspektif Al-Qur'an," Al - Tadabbur: Jurnal Ilmu Al-Qur'an dan Tafsir 2, no. 03 (December 28, 2017), doi:10.30868/at.v2i03.193. 
Syafaat adalah manifestasi dari rahmat Tuhan yang Allah berikan pada hamba yang berbuat maksiat dan para 'pendosa', seperti halnya juga merupakan bagi Rasulullah saw. untuk memberikan syafaat pada umatnya. Syafaat ini ada pada diri para Nabi, Malaikat, para ulama, para syuhada, orang-orang sholeh, anak-anak orang mukmin baik laki-laki maupun perempuan yang mati saat waktu kecil. sebagian amalan juga dapat memberikan syafaat. Alquran akan memberikan syafaat bagi siapapun yang membaca dan mengamalkannya. Puasa pun akan memberikan bagi siapapun yang melakukannya. Sesunggunya seseorang tidak dapat memberikan syafaat pada lainnya disisi Allah kecuali atas izin dan keridaan$\mathrm{Nya}^{14}$.

Dalil adanya syafaat berdasarkan firman Allah berikut ini:

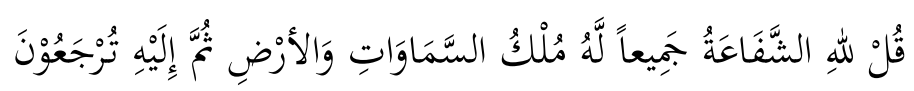

[Katakanlab: Hanya kepunyaan Allah syafaat itu semuanya. Kepunyaan-Nya kerajaan langit dan bumi. Kemudian kepada-Nyalah kamu dikembalikan]. (QS. 39/az-Zumar: 44) ${ }^{15}$

Sedangkan dalil syafaat dalam hadis antara lain adalah hadis yang diriwayatkan oleh imam al-Bukharī berikut ini:

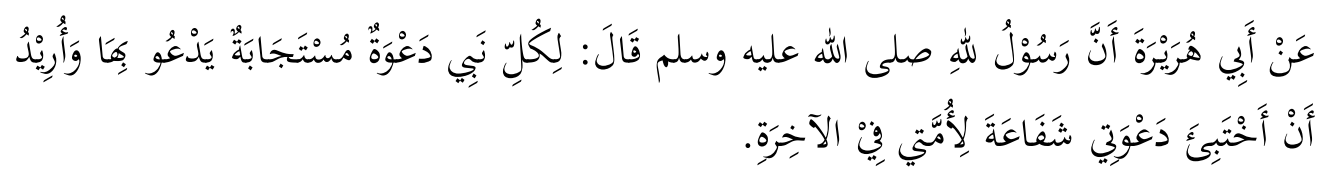

[Dari Abu Hurairah bahwa Rasulullah saw. bersabda: "Setiap Nabi mempunyai doa yang telah dikabulkan, sedang aku ingin menyimpan doaku sebagai syafä'at untuk. umatku di Akbirat nanti']. (HR. al-Bukbäri). ${ }^{16}$

\section{Konsep Syafaat dalam Kitab Sahih Muslim}

Konsep syafaat dalam hadis Sahih Muslim disebutkan dalam tiga puluh tiga hadis yang terdiri dari proses syafaat terjadi, sebab-sebab mendapatkan syafaat dan penyebutan bahwa Nabi Muhammad mendapatkan kelebihan dari Nabi lainnya dalam hal syafaat tersebut.

1. Substansi Syafaat dalam Kitab Sahih Muslim

${ }^{14}$ Sitti Trinurmi, "Hakekat dan Tujuan Hidup Manusia dan Hubungannya dengan Tujuan Pendidikan Islam," Al-Irsyad Al-Nafs: Jurnal Bimbingan dan Penyuluhan Islam 2, no. 1 (December 1, 2015), http://journal.uin-alauddin.ac.id/index.php/Al-Irsyad_Al-Nafs/article/view/2562.

15 "Qur'an Kemenag."

16 Mursalim, “Doa Dalam Perspektif Al-Qur'an,” Al-Ulum 11, no. 1 (June 1, 2011): 63-78. 
Pembahasan substansi untuk masalah ini adalah hadis tentang syafaat yang dibatasi dalam sebuah kitab (Sahih Muslim).Substansi syafaat sebagai kategori awal pada penjelasan sebelumnya juga akan diklasifikasikan dalam beberapa kategori berikut:

a) Substansi Pengetahuan Syafaat

Pengetahuan merupakan asumsi dasar dari sebuah pengetahuan atas sesuatu. Jika dihubungkan dengan substansi syafaat, maka diartikan sebagai sebuah pemahaman atas syafaat secara garis besarnya. Namun pada poin ini, pengetahuan yang dimaksud berkaitan dengan syafaat adalah bentuk-bentuk lafal syafaat yang dipakai dalam hadis dengan pengertian yang beragam dan diartikan berlainan tergantung maksudnya dan pengucapan redaksi kata sebelum dan sesudahnya. Berikut ini adalah maksud kata syafaat yang digunakan dalam Hadis Sahih Muslim:

1) Syafaat berarti memberikan pertolongan

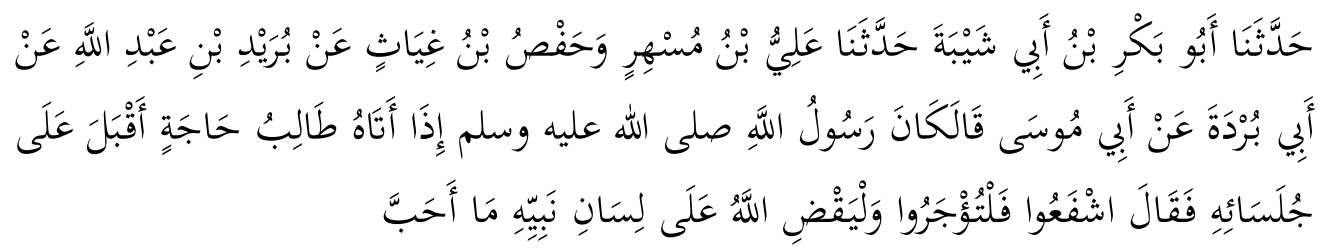

[Abu Bakr bin Abu Syaibah telah menceritakan kepada kami, (ia) berkata: 'Ali bin Mushir dan Hafsh bin Giyas telah menceritakan kepada kami dari Buraid bin 'Abdullah dari Abu Burdah dari Abu Musa, dia berkata: Apabila seorang yang meminta suatu kebutuban datang kepada Rasulullah saw, maka beliau akan menghadap kepada orang-orang yang duduk. bersama beliau seraya berkata: Berikanlah pertolongan agar kalian saling memperoleb pahala dan semoga Allah melaksanakan apa yang disenangi-Nya melalui ucapan Nabi-Nya].(HR. Muslim) $)^{17}$

Hadis di atas menjelaskan makna syafaat sebagai sebuah permintaan pertolongan yang apabila ditolong permintaan tersebut diberikan pahala oleh Allah. Permintaan ini secara umum namun dikhususkan kepada sebuah pertolongan yang diridai dan diizinkan dalam syariat oleh Allah dan Rasulullah saw.

Konsep syafaat yang berarti sebagai pertolongan juga terdapat dalam hadis imam al-Bukharī, karena hadis ini juga diriwayatkan oleh imam al-Bukharī yang terdapat dalam 3 bab dengan ibarat hadis yang berbeda-beda, yaitu bab ta'awun sebagian mukmin kepada sebagian yang lain, bab siapa yang memberi pertolongan ia dapat bagiannya dan bab kehendak dan keinginan.

\footnotetext{
${ }^{17}$ Imran, "Sahabat Nabi SAW Dalam Perspektif Sunni Dan Syi’ah."
} 
Hadis ini mengajak kepada semua mukmin untuk saling memberi bantuan dalam bentuk syafaat agar terhidar dari segala bentuk kesulitan dari mukmin yang lain dan juga hadis ini sebagai penjelas terhadap ayat 85 surah an-Nisa, yaitu memberi bantuaan kepada sesama mukmin di dunia, maka akan mendapat syafaat di akhirat ${ }^{18}$.

2) Syafaat berarti keringanan

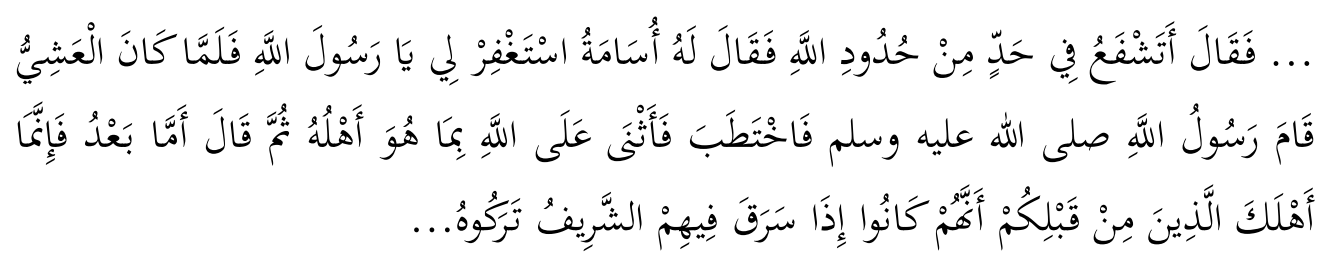

[...Bersabda Nabi saw. "Apakah kamu hendak meminta syafaat (keringanan) dalam bukum Allah (yang telah ditetapkan)!. Maka Usamah berkata kepada beliau: Mohonkanlah ampunan bagiku wahai Rasulullah". Sore harinya Rasulullah saw. berdiri dan berkhutbah, setelah memuji Allah dengan ujian yang layak untuk-Nya, beliau bersabda: "Amma Ba'du. Sesunggubnya yang membinasakan orang-orang sebelum kalian adalah manakala ada orang yang terpandang (terbormat) dari mereka mencuri, maka merekapun membiarkannya... $]^{19}$

Konsep syafaat dalam hadis ini adalah untuk meminta keringan kepada Rasulullah saw. dan bisa saja diterima permohonannya ataupun tidak. Hadis ini sebagai larangan rasul untuk memberikan syafaat kepada siapa saja yang sudah ditetapkan had (hukuman) baginya, namun bila hukuman belum dijatuhkan lalu dia meminta pertolongan atau keringanan atau syafaat kepada atasnya, maka hal ini dibolehkan memberi bantuan syafaat menurut mayoritas ulama ${ }^{20}$.

b) Substansi Tujuan Inti Syafaat

Inti tujuan syafaat sebagaimana telah diketahui sebelumnya pada landasan teori adalah untuk mengurangi atau meringankan sebuah dosa atau kesalahan seseorang manusia oleh Allah atau manusia lain yang diberikan hak-Nya dan ridaNya. Dalam hadis Sahih Muslim terdapat beberapa hadis yang menjelaskaninti

\footnotetext{
Iman)."

${ }^{18}$ Supian, "Metode Syarah Fath Al-BariI (Studi Syarah Hadis pada bab Halawah al-

${ }^{19}$ Kurnia Muhajarah, "Konsep Doa: Studi Komparasi Konsep Do'a Menurut M. Quraish Shihab dan Yunan Nasution dan Relevansinya dengan Tujuan Pendidikan Islam," HIKMATUNA 2, no. 2 (December 2, 2016), doi:10.28918/hikmatuna.v2i2.960.

${ }^{20}$ Minggusta Juliadarma, “Konsep Pendidikan Islam Dalam Kitab Fathul Baari,” EL Bidayab: Journal of Islamic Elementary Education 1, no. 1 (2019): 111-32, doi:https://doi.org/10.33367/jiee.v1i1.741.
} 
tujuandari syafaat tersebut, berikut ini adalah inti tujuan syafaat serta hadis-hadis yang membahasnya:

1) Meringankan Azab Neraka

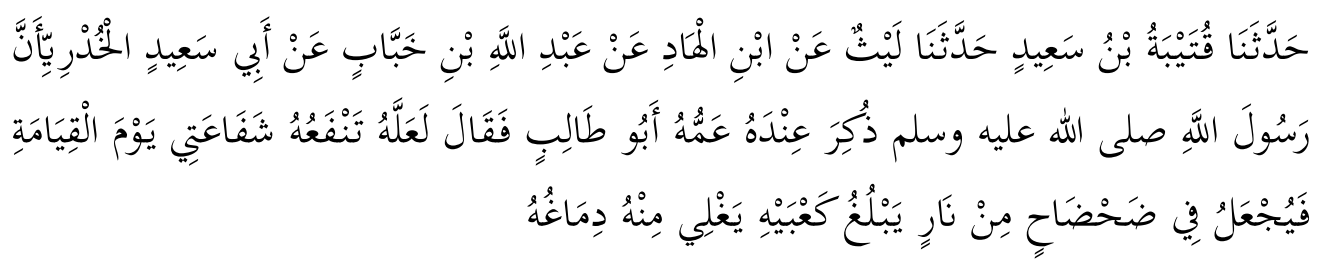

Qutaibah bin Said telah menceritakan kepada kami, (ia) berkata: al-Laits telah menceritakan kepada kami dari Ibnu al-Had dari Abdullab bin Khabbab dari Abu Sa id al-Khudri bahwa Rasulullah saw. pernah disebutkan di sisinya tentang pamannya Abu Talib. Maka Rasulullah saw. bersabda: "Semoga syafaatku dapat menolongnya pada hari kiamat sehingga dia diletakekan di dalam Neraka yang paling landai, apinya mencapai mata kakinya yang membuat otaknya mendidib].(HR. Muslim) ${ }^{21}$

Salah satu syafaat lainnya selain syafaat yang mengeluarkan umat manusia dari neraka dan memasukkan mereka ke dalam syurga adalah syafaat khusus bagi Abu Țālib yang dijelaskan pada hadis di atas. Syafaat untuk paman Nabi ini adalah keringanan azab neraka, maksudnya keringanan dalam penempatan tempat dalam neraka.

2) Mengeluarkan dari Neraka Memasukannya ke dalam Surga

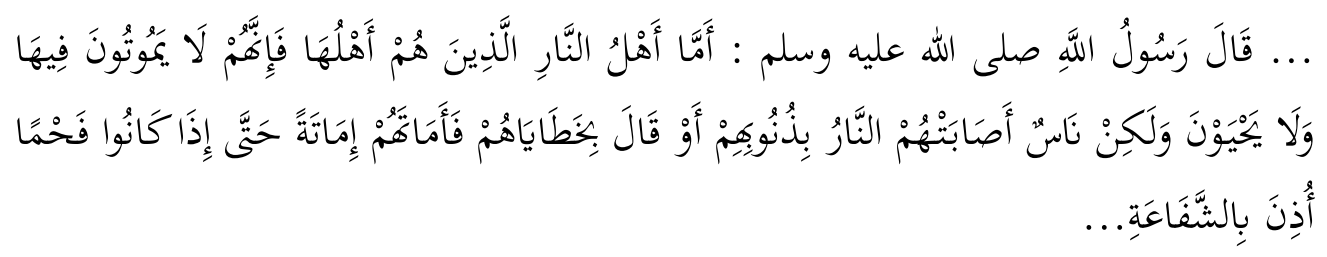

[... Rasulullab saw. bersabda: Adapun penduduk neraka yang mana mereka adalah penduduknya, maka mereka tidake akan mati di dalamnya dan tidak pula bidup. Tetapi orang yang terkena siksa neraka karena dosa mereka atau kesalahan mereka maka Allab mematikan mereka bingga apabila mereka telah hangus terbakar, maka diizinkanlah pemberian syafaat...] (HR. Muslim) ${ }^{22}$

Otoritas Allah sebagai Khaliq juga sebagai penghukum atas makhluknya tidak dapat dipungkiri dan disanggah. Dalam Hadis di atas disebutkan bahwa orang yang membuat dosa dan masuk neraka pun walau mendapat syafaat tetap

${ }^{21}$ Afwadzi, "Tinjauan Semiotika Atas Pemahaman Hadith Dalam Kitab Fath Albari Karya Ibn Hajar Al'Asqalani."

${ }^{22}$ Muslimah, Konsep Syafaat Menurut Pandangan Mubammad Quraish Shihab (Analisis Terbadap Tafsir Al-Misbab). 
harus menjalani hukuman di dalam neraka terlebih dahulu hingga waktu syafaat yang diberikan dan telah diridai oleh Allah boleh diterima. Pemberian syafaat ini berguna bagi mereka untuk sebuah " $t i k e t$ " untuk dapat keluar dari neraka dan dimasukkan ke dalam surga.

c) Substansi Batasan Syafaat

Batasan merupakan sebuah syarat atau aturan yang ditetapkan untuk suatu kepentingan. Misalnya batasan dalam salat subuh adalah dua rakaat, maka tidak dapat dikerjakan melebihi dua rakaat atau kurang dari dua rakaat. Batasan syafaat hanya diberikan kepada golongan manusia yang beriman dijelasakan dalam Sahih Muslim seperti berikut:

1) Mengucap Dua Kalimat Syahadah

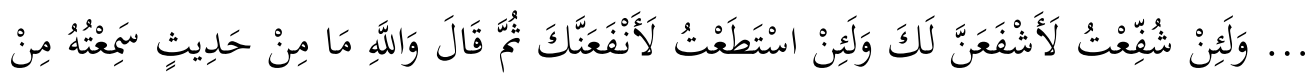

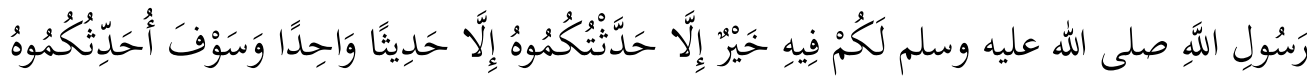

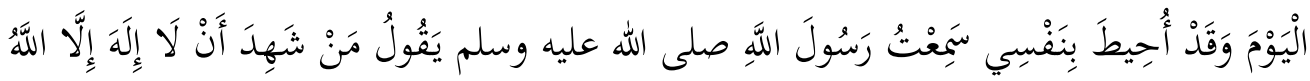

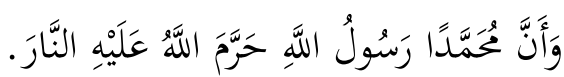

[...dan jikea aku diberi syafaat, maka aku memberikan syafaat untukmu, serta jika aku mampu, maka aku memberikan manfaat untukmu. Kemudian dia berkata: Demi Allah, tidaklah ada suatu hadis yang aku dengar dari Rasulullah saw. untuk kalian yang di dalamnya terdapat kebaikan melainkan pasti aku menceritakannya kepada kalian, kecuali satu hadis, dan saya akan menceritakan kepadamu pada hari ini. Dan sungguh aku meresapi hal tersebut pada diriku. Aku mendengar Rasulullah saw. bersabda: "Barangsiapa bersaksi bahwa tidak ada tuhan (yang berbak disembah) selain Allah, dan bahwa Mubammad utusan Allah, niscaya Allab mengharamkan neraka atasnya]. (HR. Muslim) $)^{23}$

2) Tidak Menyekutukan Allah

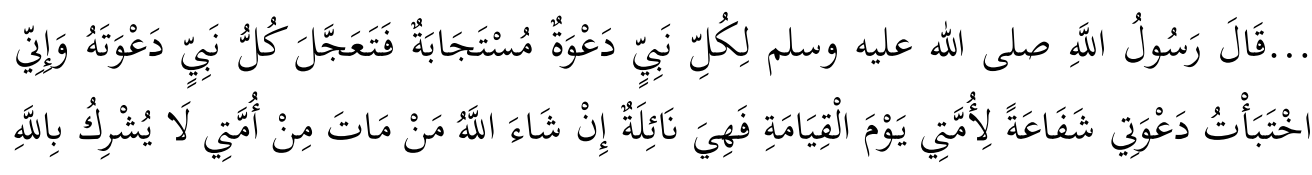

شَيْيًَا.

... "Rasulullah saw. bersabda: "Setiap Nabi memiliki doa yang mustajab, maka setiap nabi menyegerakan doanya, dan sesunggubnya aku menyembunyikan doaku sebagai syafaat bagi

23Jasmin, “Konsep Syafaat Dalam Rencana Total Allah.” 
umatku pada hari kiamat. Dan insya Allah syafaatku akan mencakup orangyang mati dari kalangan umatku yang tidak mensyirikean Allab dengan sesuatu apa pun". (HR. Muslim) ${ }^{24}$

2. Sebab Mendapatkan Syafaat dalam Kitab Sahih Muslim

Berkaitan dengan sebab-sebab mendapat syafaat ini, ada beberapa hadis di dalam Sahih Muslim yang menyebutkannya dan menjelaskannya, diantaranya adalah:

a. Membaca Alquran

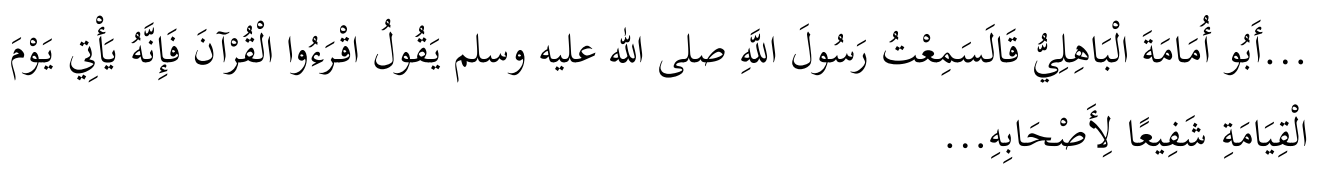

[...Abu Umamah al-Babili telah menceritakan kepadaku, (ia) berkata: Saya mendengar Rasulullah saw. bersabda: "Bacalah Alquran, karena ia akan datang memberi syafaat kepada para pembacanya pada hari kiamat nanti...]. (HR. Muslim) ${ }^{25}$

b. Bersabar atas Kesusahan Tinggal di Kota Madinah

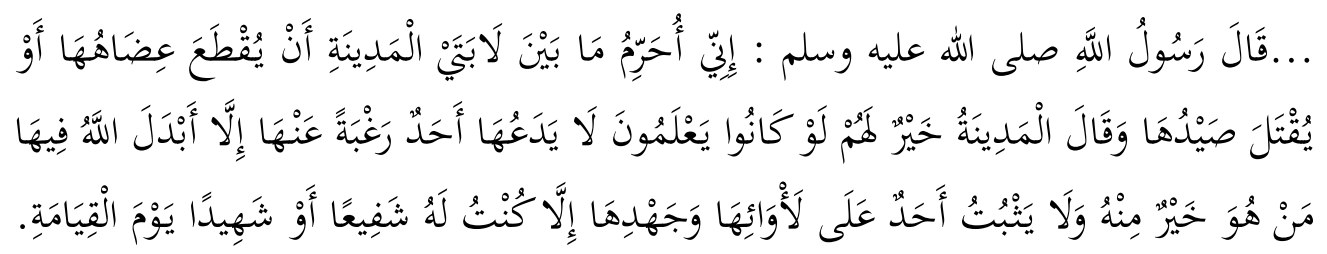

[...Rasulullah saw. bersabda: Aku menjadikan kota Madinah sebagai tanah haram, yaitu antara kedua bukitnya yang berbatu-batu hitam. Jangan ditebang pepohonannya, dan jangan pula dibunuh hewan buruannya. Dan beliau juga bersabda: "Kota Madinah lebih baik bagi mereka jikea sekiranya mereka mengetahuinya. Orang yang meninggalkan kota itu karena tidak senang kepadanya, maka Allab akan menggantinya dengan orang yang lebih baik dari padanya. Seorang yang betah tinggal di kota itu dalam kesusahan dan kesulitan hidup, maka aku akan memberinya syafaatku atau menjadi saksi baginya di hari kiamat nanti.](HR. Muslim) ${ }^{26}$

${ }^{24}$ Hasiah, "Syirik Dalam Perspektif Al-Qur'an," Yurisprudentia: Jurnal Hukum Ekonomi 3, no. 1 (2017): 83-102.

${ }^{25}$ Mursalim, "Doa Dalam Perspektif Al-Qur'an."

${ }^{26}$ Ummu Salamah Ali, "Peradaban Islam Madinah (Refleksi Terhadap Primordialisme Suku Auz Dan Khazraj)," Kalimah: Jurnal Studi Agama Dan Pemikiran Islam 15, no. 2 (2017): 191 204, doi:10.21111/klm.v15i2.1495. 
c. Meninggal di Kota Madinah

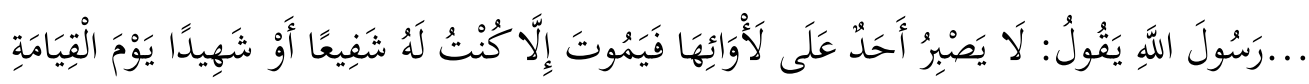

إذِاَ كَانَ مُسنْلِمًا

[...Rasulullah saw. bersabda: Tidaklah seseorang bersabar terhadap kesulitan bidup di Madinah lalu dia mati, melainkan aku akan menjadi penolongnya (atau saksinya) kelake pada hari kiamat, jik. a orang tersebut adalah seorang muslim].(HR. Muslim) ${ }^{27}$

d. Mengikuti Ucapan Azan, bersalawat dan membaca do'a setelah azan

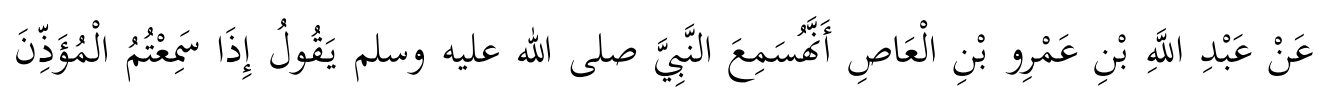

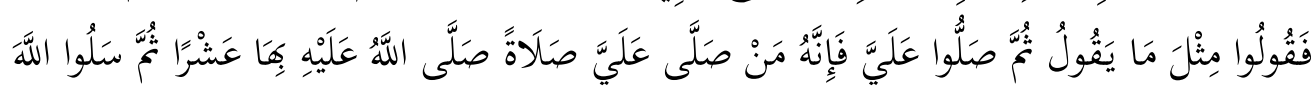

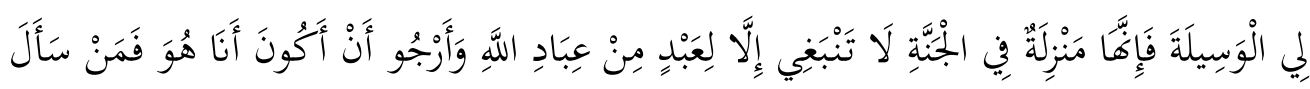

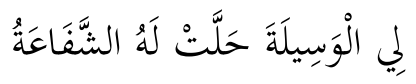

[Abdullab bin Amru bin al-Aș bahwa dia mendengar Nabi saw. bersabda: Apabila kalian mendengar muazin (mengumandangkan azan) maka ucapkanlah seperti yang dia ucapkan, kemudian bershalawatlah atasku, karena orang yang bershalawat atasku dengan satu shalawat, niscaya Allah akan bershalawat atasnya dengannya sepulub kali, kemudian mintalah kepada Allah wasilah untukk.u, karena ia adalah suatu tempat di surga, tidaklab layak tempat tersebut kecuali untuk seorang hamba dari hamba-hamba Allah, dan saya berharap agar saya menjadi hamba tersebut. Dan barangsiapa memintakan wasilah untuke.u, maka syafaat halal untuknya].(HR. Muslim) $)^{28}$

e. Salat dan Doa Seratus Orang Muslim terhadap Jenazah

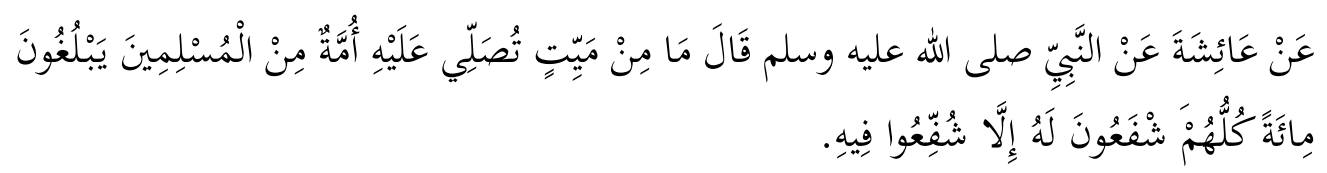

Dari Aisyah dari Nabi saw, beliau bersabda: "Mayatyang dishalatkan oleb kaum muslimin dengan jumlah melebihi seratus orang, dan semuanya mendo'akannya, maka doa mereka untuknya akan dikabulkean.] (HR. Muslim) ${ }^{29}$

${ }^{27}$ Yusno Abdullah Otta, "Madinah Dan Pluralisme Sosial (Studi Atas Kepemimpinan Rasulullah Saw)," Jurnal Ilmiah Al-Syir'ab 8, no. 2 (2010), doi:10.30984/as.v8i2.21.

${ }^{28}$ Mursalim, "Doa Dalam Perspektif Al-Qur'an."

${ }^{29} \mathrm{Ibid}$. 
f. Doa Empat Puluh Orang Mukmin terhadap Jenazah

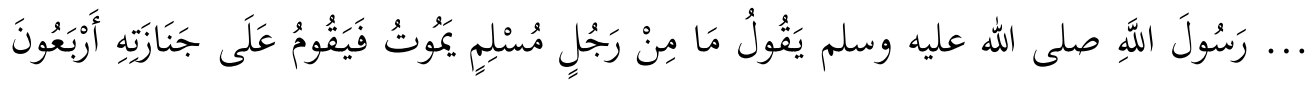

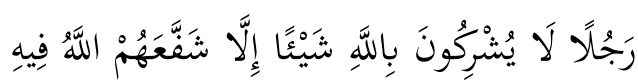

[...Rasulullah saw. bersabda: "Tidaklah seorang muslim meninggal dunia, dan dishalatkan oleb lebih dari empat pulub orang, yang mana mereka tidak menyekutukan Allah, niscaya Allah akan mengabulkan doa mereka untuknya"].(HR. Muslim) $)^{30}$

3. Pemberi dan Penerima Syafaat dalam Kitab Sahih Muslim

Sebagaimana dipahami dari hadis Muslim, bahwa Rasul adalah orang yang istimewa dalam hal memberi bantuan baik di dunia sebagai petunjuk demikian juga diakhirat sebagai pemberi syafaat kepada umatnya. Hal ini wajib diimani oleh setiap orang muslim yang meyakini ketauhidannya kepada Allah swt. salah satu upaya Rasul di akhirat adalah membebaskan manusia yang bertauhid dari neraka dan masuk surga yang merupakan tujuan akhir manusia.

Hadis Muslim berikut menjelaskan pemberi dan penerima syafaat, serta waktu mendapat syafaat sebagaimana terlihat dalam hadis imam Muslim berikut ini:

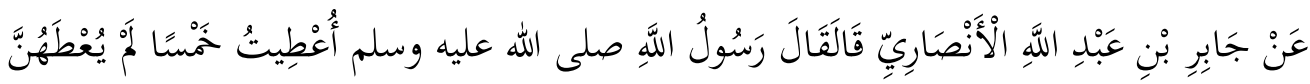

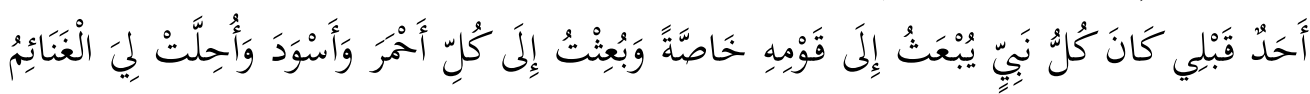

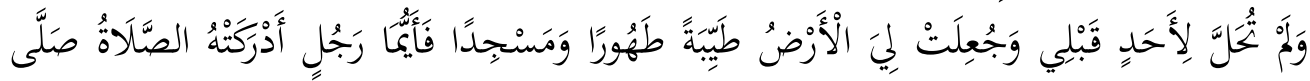

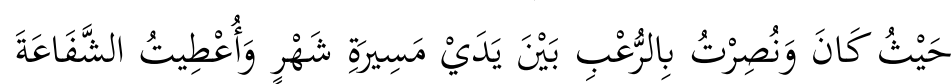

[Dari Jabir bin Abdullah al-Anshari dia berkata: Rasulullah saw. bersabda: Aku diberikan lima perkara yang mana belum pernah diberikan kepada seorang pun sebelumku. Pertama, dabulu setiap Nabi diutus kepada kaumnya secara kbusus, sedangkan aku diutus kepada setiap bangsa merah dan hitam. Kedua, harta ghanimah (rampasan perang) dihalalkan untukku, namun tidak dihalalkan untuk seorang pun sebelumku. Ketiga, dan bumi itu dijadikan untukkeu dalam keadaan suci dan mensucikan dan (sebagai) masjid juga, maka siapa pun laki-laki yang mana waktu shalat mendapatinya maka dia bisa shalat di mana pun dia berada. Keempat, aku ditolong dengan rasa takut (yang merasuk, pada musuh di hadapanku) sejauh jarak perjalanan satu bulan. Kelima, aku diberi syafaat].(HR. Muslim) ${ }^{31}$

${ }^{30}$ Ahmad Sarwat, Fiqib Shalat Jenazah (Jakarta: Rumah Fiqih Publishing, 2018), 36.

${ }^{31}$ Jasmin, "Konsep Syafaat Dalam Rencana Total Allah.” 


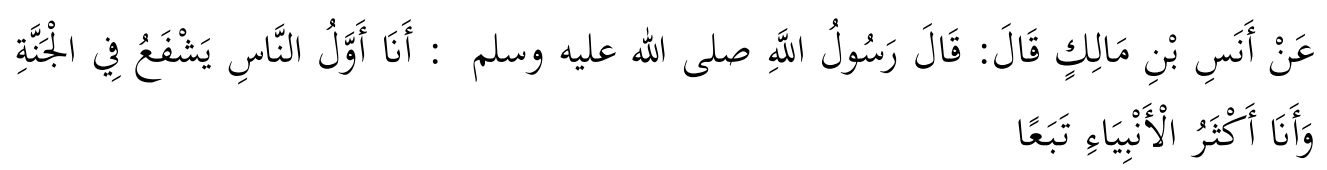

Dari Anas bin Malik dia berkata: Rasulullah saw. bersabda: Aku adalab manusia pertama yang memberi syafaat (untuk masuk) ke surga, dan aku adalah Nabi yang paling banyak. pengikutnya].(HR. Muslim) $)^{32}$

Dalam hadis pertama poin ini, terlihat keistimewa Rasul sebagai pemberi syafaat serta perhatian Rasul kepada umatnya, bahwa syafaat itu sudah dipersiapkan oleh Allah kepada Rasulnya dari awal untuk dapat membantu umatnya. Kemudian pada hadis kedua menjelaskan bahwa Rasul sebagai orang pertama dalam memberi bantuan, sebelum yang lain seperti malaikat, orang-orang mukmin, sudah duluan Rasul membantu umatnya.

Terdapat juga hadis lain yang menjelaskan tentang syafaat pada hari kiamat dengan lengkap dan juga menjelaskan ahwal hari akhirat dalamnya, yaitu manusia akan dapat melihat Allah seperti manusia melihat matahari atau bulan ketika di dunia, dan menusia akan melihat Allah serta akan medapatkan syafaat dari Rasul, malaikat, orang-orang mukmin akan memberi syafaat kepada mukmin yang lain ${ }^{33}$.

Hari akhirat, setelah manusia menjalani siksa terhadap kesalahanya, maka manusia dapat syafaat masuk surga dan juga dapat memberikan syafaat kepada saudaranya yang masih berada dalam neraka, kemudian masuk surga sebagai bentuk dari syafaat sesama mukmin.

Berikut ini terdapat dalam hadis riwayat imam Muslim tentang orang yang tidak mendapatkan syafaat di akhirat, yaitu:

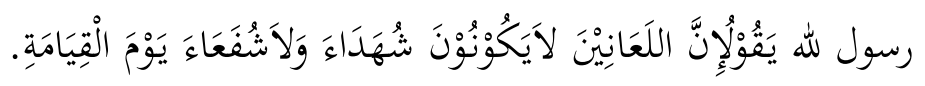

[Rasulullah saw. bersabda: Sesunggubnya para pelaknat itu tidak akan dapat menjadi syubada' (orang-orang yang menjadi saksi) dan tidak pula dapat memberi syafaat pada hari kiamat kelak]. (HR. Muslim) $)^{34}$

Hadis ini menjelaskan ketentuan syafaat tidak dapat dinikmati oleh orang yang suka melaknat saudaranya atau tidak dapat memberikan syafaat kepada

${ }^{32}$ Damanik, "Urgensi Studi Hadis di UIN Sumatera Utara."

${ }^{33}$ M. Mu'min, "Study Syarah Shahih Al-Bukhari; At-Taudhih Li Syarhi Al-Jami' Ash-Shahih Ibn Al-Mulaqqin," Diroyah: Jurnal Studi Ilmu Hadis 3, no. 1 (2018), doi:10.15575/diroyah.v3i1.3895.

${ }^{34}$ Sukron Abdilah, "Eskatologi Kematian dan Kemenjadian Manusia," Jaqfi: Jurnal Aqidah dan Filsafat Islam 1, no. 1 (October 30, 2016): 121-34, doi:10.15575/jaqfi.v1i1.1691. 
saudaranya yang mukmin di akhirat, dia juga tidak dapat dijadikan saksi terhadap permasalahan yang terjadi di kalangan manusia kerena fasik. Dan diakhirat juga tidak dapat menjadi saksi atas tersampainya risalah Rasul kepada umat manusia ketika di dunia ${ }^{35}$. Hadis ini juga menjelaskan bahwa orang-orang mukmin di hari akhirat akan menjadi saksi bahwa risalah Rasul tersampaikan. Begitu juga dengan syafaat akan diberikan kepada orang yang tidak fasik, sedangkan orang yang suka melaknat, dia digolongkan kepada kolompok orang fasik yang tidak diterima persaksiannya dunia akhirat ${ }^{36}$.

\section{Waktu Terjadi Syafaat dalam Kitab Sahih Muslim}

Beberapa riwayat yang tedapat dalam sahih muslim dapat disimpulkan bahwa yafaat dapat terjadi di dunia dan juga di akhirat, namun syafaat dunia adalah bersifat maknawi, sedangkan yang hakikat adalah syafaat yang terjadi di akhirat.

a. Syafaat Dunia

Menurut hadis riwayat Muslim syafaat secara umum dapat terjadi di dunia dan secara kusus hanya terjadi di akhirat. Syafaat yang terjadi di dunia bermakna pertolongan seseorang kepada orang lain atau seorang penguasa memberikan kebebasan dari sanksi tertentu kepada rakyatnya atau bahkan pertolongan Rasul kepada sahabatnya agar tidak dihukum. Makna lain dari syafaat yang berbentuk bantuan adalah doa yang di doakan kepada orang yang telah meninggal dengan cara membantu melalui salat janazah. Makna syafaat yang terjadi di dunia terdapat pada hadis antara lain:

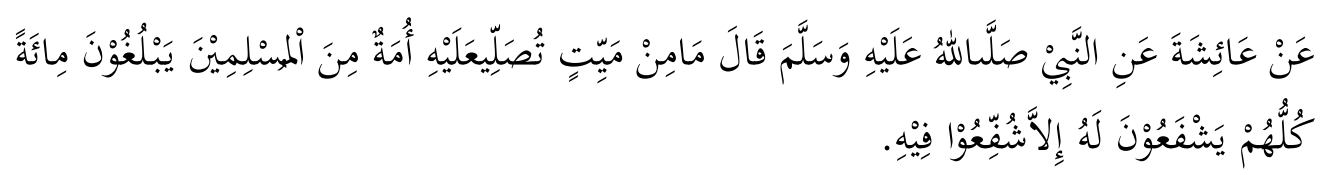

[Dari Aisyah dari Nabi saw., beliau bersabda: Mayat yang disalatkan oleh kaum muslimin dengan jumlah melebibi seratus orang, dan semuanya mendoakannya, maka doa mereka untuknya akan dikabulkan. Lalu saya menceritakannya kepada Syu'aib bin Habhab, maka ia pun berkata: Anas bin Malik telah menceritakannya kepadaku dari Nabi saw]. ${ }^{37}$

Syafaat dalam hadis ini diartikan sebagai doa kepada orang yang telah meninggal, yaitu dari doa tersebut yang diharapakan adalah adanya keringanan atau kelepasan dari azab kubur dan menjadi kebebasan di akhirat dengan masuk surga. oleh karenanya, apabila didoakan oleh jumlah yang telah disebutkan, maka

${ }^{35}$ Ibid.

${ }^{36}$ Umar Latif, "Konsep Mati Dan Hidup Dalam Islam (Pemahaman Berdasarkan Konsep Eskatologis )," Jurnal Al-Bayan: Media Kajian Dan Pengembangan Ilmu Dakwah 22, no. 2 (2016), doi:10.22373/albayan.v22i34.875. Khazraj)."

${ }^{37}$ Ali, "Peradaban Islam Madinah (Refleksi Terhadap Primordialisme Suku Auz Dan 
Allah akan menerima doanya dan memberikan sesuai dengan permintaan. Dalam satu riwayat dijelaskan bahwa doanya akan dikabulkan Allah bila yang berdoa itu berjumlah tiga saf salat dan syafaat pun akan diperolehnya sebagai bantuan dari saudara-saudaranya yang masih hidup ${ }^{38}$

b. Syafaat Akhirat

Syafaat yang hakikat menurut Muslim adalah terjadi di akhirat, syafaat yang berlaku di akhirat menurutnya adalah menyegerakan umat manusia dalam penantiannya di padang mahsyar, mempercepat hisap (perhitungan amal), segera masuk surga, dikeluarkan dari neraka dan meningkatkan derajat ahli surga. Makna syafaat yang terjadi di akhirat terdapat dalam hadisnya antara lain:

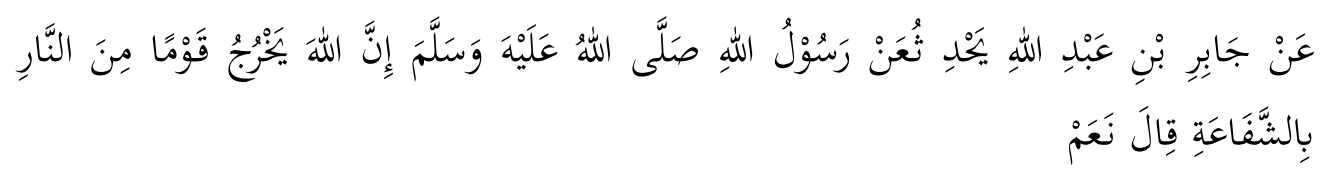

[Telah menceritakan kepada kami Abu ar-Rabi' telah menceritakan kepada kami Hammad bin Zaid dia berkata: Saya berkata kepada Amru bin Dinar, Apakah kamu mendengar Jabir bin Abdullah menceritakan hadis dari Rasulullah saw. bersabda: Sesunggubnya Allah mengeluarkan suatu kaum dari neraka dengan syafaat? ' Amru menjawab, Ya]. (HR. Muslim) ${ }^{39}$

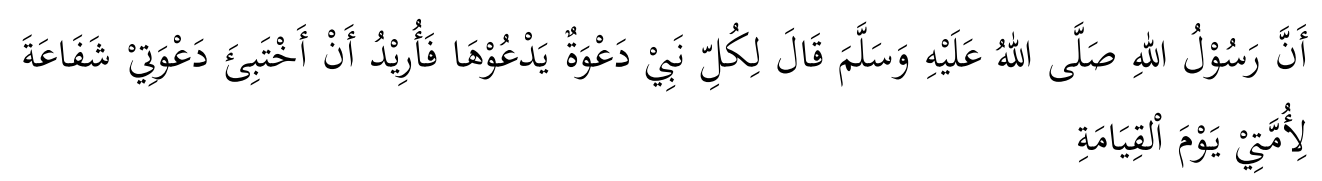

[bahwa Rasul saw. bersabda: Setiap Nabi memiliki doa yang dia panjatkan, maka aku berkeinginan untuk menyimpan doaku sebagai syafaat bagi umatku]. (HR. Muslim) ${ }^{40}$

Dalam dua hadis tersebut terdapat pebedaan berkaitan dengan syafaat, yaitu dalam hadis riwayat al-Bukhārī syafaat hanya terjadi di akhirat dan maksud dengan syafaat adalah bantuan langsung dari Rasulullah atau lainnya. Sedangkan dalam riwayat Muslim syafaat bisa bermakna pertolongan dan doa, dan dapat terjadi di dunia, alam kubur dan di akhirat, namun syafaat yang hakikat adalah di akhirat.

${ }^{38}$ Mursalim, "Doa Dalam Perspektif Al-Qur'an."

${ }^{39}$ Abdilah, "Eskatologi Kematian dan Kemenjadian Manusia."

${ }^{40}$ Farih, "Paradigma Pemikiran Tawassul Dan Tabarruk Sayyid Ahmad Bin Zaini Dahlan Ditengah Mayoritas Teologi Madzhab Wahaby.” 


\section{Syarat Terjadi Syafaat dalam Kitab Sahih Muslim}

Manusia akan dapat menikmati syafaat harus dengan syarat-syarat tertentu, yaitu adanya kerelaan dari Allah dan keinginan-Nya, adanya keimanan walau sebesar biji sawi, dan adanya mengucapkan kalimat kalimat là iläha illa Allah (tidak ada Tuhan selain Allah). Syafaat yang diperoleh oleh manusia dengan kerelaan dan kehendak dari Allah serta adanya keimanan tercermin dalam hadis berikut ini:

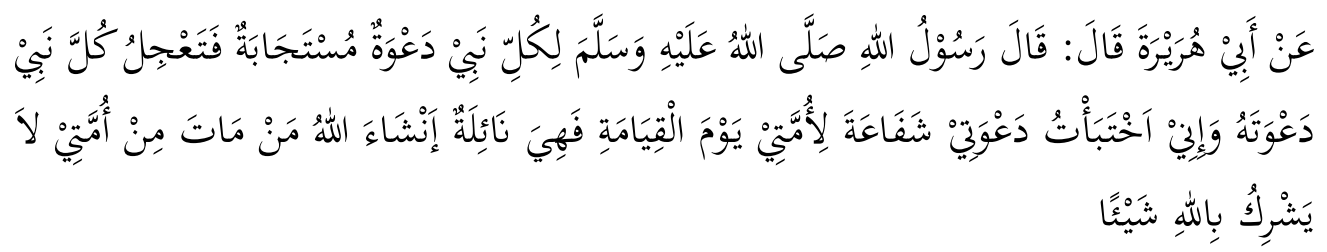

[Dari Abu Hurairah dia berkata: Rasulullah saw. bersabda: Setiap Nabi memiliki doa yang mustajab, maka setiap nabi menyegerakan doanya, dan sesunggubnya aku menyembunyikan doaku sebagaisyafaat bagi umatku pada hari kiamat. Dan insya Allah syafaatku akan mencakup orang yang mati dari kalangan umatku yang tidak mensyirikkan Allab dengan sesuatu apa pun]. (HR. Muslim)

Sedangkan syarat mendapatkan syafaat dengan adanya mengucapkan la ilaba illa Allabyaitu terdapat dalam hadis berikut ini:

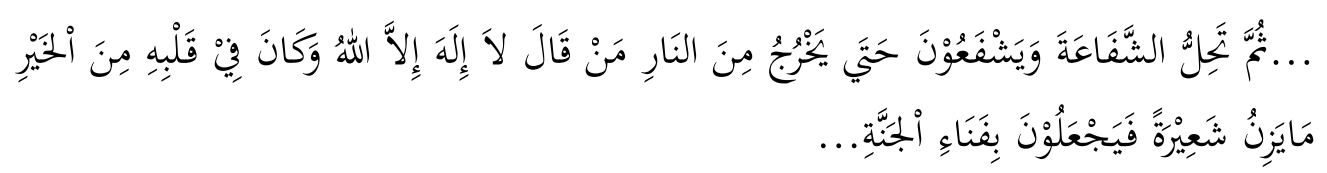

[... Kemudian syafaat diĩinkan. Mereka pun meminta syafaat, sehingga mereka dapat keluar dari Neraka, yaitu orang yang mengucapkan, Laa Ilaaha illallabu (Tidak ada tuban (yang berbak disembah) selain Allah, dan dabulu di hatinya terdapat kebaikan seberat biji gandum. Mereka akan ditempatkan di balaman Surga,...] (HR. Muslim). ${ }^{41}$

Hadis dengan maksud yang sama juga terdapat dalam riwayat al-Bukhārī yang menyebutkan bahwa membaca la ilaha illa Allah akan memperoleh syafaat yang besar bagi orang yang membacanya ${ }^{42}$.

${ }^{41}$ M. Ma'ruf, "Konsep Mewujudkan Keseimbangan Hidup Manusia Dalam Sistem Pendidikan Islam,” Al-Makrifat: Jurnal Kajian Islam 4, no. 2 (2019): 123-37.

${ }^{42}$ Muslimah, Konsep Syafaat Menurut Pandangan Mubammad Quraish Shihab (Analisis Terbadap Tafsir Al-Misbah). 


\section{Kesimpulan}

Setelah dikemukakan bahasan di atas dapat dikemukakan beberapa hal berikut. Kata syafaat di dalam Hadis menunjukkan kepada makna bahwa syafaat itu adalah pertolongan langsung dari Rasulullah, Malaikat, orang-orang mukmin pada hari kiamat untuk mendapatkan kebaikan atau menolak keburukan. Imam Muslim menyebutkan sebanyak tiga puluh hadis tentang syafaat. Semua hadis tersebut menjelaskan tentang syafaat mulai dari proses terjadi syafaat, sebab-sebab mendapatkan syafaat, pemberi dan penerima syafaat, waktu terjadi syafaat dan syarat-syarat untuk mendapatkan syafaat. Bantuan dalam bentuk syafä'at bisa diperoleh oleh penerima di dunia dan di akhirat. Syafaat akan diperoleh dengan Izin dan rela dari Allah serta kehendak dari-Nya. Pemberi syafáa at adalah Rasul, malaikat, orang mukmin, syuhada, penguasa. Orang-orang yang mendapat syafä át adalah Rasul, keluarga Rasul, Abu Talib, pelaku dosa, dan orang meninggal yang didoakan oleh orang yang hidup karena syafaat selalu bermakna dan berkonotasi positif. Adapun Sebab-sebab mendapatkan syafäat adalah Izin Allah, Ridha, Syahädah, iman, baca doa setelah azan dan sabar atas kesusahan tinggal di kota madinah, meninggal di kota madinah (melaksanakan haji), mengikuti ucapan azan dari muazzin bersalawat dan membaca doa setelah azan, salat janazah oleh 100 atau 40 orang. Waktu mendapatkan syafäa at di dunia dan akhirat dengan masuk surga atau bebas dari siksaan neraka.

\section{Bibliografi}

Abdilah, Sukron. "Eskatologi Kematian dan Kemenjadian Manusia." Jaqfi: Jurnal Aqidah dan Filsafat Islam 1, no. 1 (October 30, 2016): 121-34. doi:10.15575/jaqfi.v1i1.1691.

Afriyanti, Yuli Ayu. "Sang Pemberi Syafaat (Mengenal Para Pemberi Syafaat Dihari Akhir)." INA-Rxiv, December 30, 2018. doi:10.31227/osf.io/cgxy9.

Afwadzi, Benny. "Tinjauan Semiotika Atas Pemahaman Hadith Dalam Kitab Fath Albari Karya Ibn Hajar Al'Asqalani." Al-A'raf: Jurnal Pemikiran Islam Dan Filsafat 17, no. 1 (June 30, 2020$): 97$. doi:10.22515/ajpif.v17i1.1935.

Ali, Ummu Salamah. "Peradaban Islam Madinah (Refleksi Terhadap Primordialisme Suku Auz Dan Khazraj)." Kalimah: Jurnal Studi Agama 
646 | AL QUDS : Jurnal Studi Alquran dan Hadis vol. 5, no 2, 2021

Dan Pemikiran Islam 15, no. 2 (2017): 191-204. doi:10.21111/klm.v15i2.1495.

Bafadhol, Ibrahim. "Tujuan Hidup dalam Perspektif Al-Qur'an.” Al - Tadabbur: Jurnal Ilmu Al-Qur'an dan Tafsir 2, no. 03 (December 28, 2017). doi:10.30868/at.v2i03.193.

Damanik, Agusman. "Urgensi Studi Hadis di UIN Sumatera Utara." SHAHIH (Jurnal Kewahyuan Islam) 1, no. 1 (August 29, 2018). doi:10.51900/shahih.v1i1.1886.

Farih, Amin. "Paradigma Pemikiran Tawassul Dan Tabarruk Sayyid Ahmad Bin Zaini Dahlan Ditengah Mayoritas Teologi Madzhab Wahaby." Jurnal Theologia 27, no. 2 (December 27, 2016): 279-304. doi:10.21580/teo.2016.27.2.1069.

Hasiah. "Syirik Dalam Perspektif Al-Qur'an.” Yurisprudentia: Jurnal Hukum Ekonomi 3, no. 1 (2017): 83-102.

Imran, Muhammad. "Sahabat Nabi SAW Dalam Perspektif Sunni Dan Syi'ah (Pengaruhnya Pada Kesahihan Hadis)." Aqlam: Journal of Islam and Plurality 1, no. 1 (January 31, 2018). doi:10.30984/ajip.v1i1.497.

Jasmin, Mesakh. "Konsep Syafaat Dalam Rencana Total Allah.” Jurnal Jaffray 4, no. 1 (June 1, 2006): 34-40. doi:10.25278/jij1.v4i1.133.

Juliadarma, Minggusta. "Konsep Pendidikan Islam Dalam Kitab Fathul Baari." EL Bidayah: Journal of Islamic Elementary Education 1, no. 1 (2019): 111-32. doi:https://doi.org/10.33367/jiee.v1i1.741.

Latif, Umar. "Konsep Mati Dan Hidup Dalam Islam (Pemahaman Berdasarkan Konsep Eskatologis )." Jurnal Al-Bayan: Media Kajian Dan Pengembangan Ilmu Dakwah 22, no. 2 (2016). doi:10.22373/albayan.v22i34.875.

Ma’ruf, M. "Konsep Mewujudkan Keseimbangan Hidup Manusia Dalam Sistem Pendidikan Islam." Al-Makrifat: Jurnal Kajian Islam 4, no. 2 (2019): 12337.

Muhajarah, Kurnia. “Konsep Doa: Studi Komparasi Konsep Do’a Menurut M. Quraish Shihab dan Yunan Nasution dan Relevansinya dengan Tujuan 
Pendidikan Islam." HIKMATUNA 2, no. 2 (December 2, 2016). doi:10.28918/hikmatuna.v2i2.960.

Mu'min, M. "Study Syarah Shahih Al-Bukhari; At-Taudhih Li Syarhi Al-Jami' Ash-Shahih Ibn Al-Mulaqqin.” Diroyah : Jurnal Studi Ilmu Hadis 3, no. 1 (2018). doi:10.15575/diroyah.v3i1.3895.

Munawwir, A.W. Kamus Al-Munawwir Arab-Indonesia Terlengkap. Surabaya: Progressif, 1997.

Mursalim. "Doa Dalam Perspektif Al-Qur'an." Al-Ulum 11, no. 1 (June 1, 2011): 63-78.

Muslimah, Iim. Konsep Syafaat Menurut Pandangan Mubammad Quraish Shibab (Analisis Terbadap Tafsir Al-Misbab). Jakarta: IIQ, 2017.

Najib, Khotim Hanifudin, and Achmad Habibullah. "Konstruksi Sosial Islam Moderat Jamaah Maiyah Mocopat Syafaat Pada Generasi Milenial Di Yogyakarta." Fikri: Jurnal Kajian Agama, Sosial Dan Budaya 5, no. 2 (December 31, 2020): 171-82. doi:10.25217/jf.v5i2.1175.

Otta, Yusno Abdullah. "Madinah Dan Pluralisme Sosial (Studi Atas Kepemimpinan Rasulullah Saw).” Jurnal Ilmiah Al-Syir'ah 8, no. 2 (2010). doi:10.30984/as.v8i2.21.

“Qur'an Kemenag." Accessed August 17, 2021. https://quran.kemenag.go.id/.

Sarwat, Ahmad. Fiqib Shalat Jenazah. Jakarta: Rumah Fiqih Publishing, 2018.

Supian, Aan. "Metode Syarah Fath Al-BariI (Studi Syarah Hadis pada bab Halawah al-Iman)." Nuansa: Jurnal Studi Islam dan Kemasyarakatan 10, no. 1 (June 10, 2017). doi:10.29300/nuansa.v10i1.632.

Trinurmi, Sitti. "Hakekat dan Tujuan Hidup Manusia dan Hubungannya dengan Tujuan Pendidikan Islam." Al-Irsyad Al-Nafs: Jurnal Bimbingan dan Penyuluban Islam 2, no. 1 (December 1, 2015). http://journal.uinalauddin.ac.id/index.php/Al-Irsyad_Al-Nafs/article/view/2562. 
648 | AL QUDS : Jurnal Studi Alquran dan Hadis vol. 5, no 2, 2021

Halaman kosong 